\title{
A review of consecutive cardiac arrests in 2002 and 2007 at a regional hospital in Denmark: a retrospective cohort study
}

\author{
Henriette Ullerup-Aagaard ${ }^{1 *}$, Søren Nielsen², Mikkel Brabrand ${ }^{1,3}$ \\ From 4th Danish Emergency Medicine Conference \\ Roskilde, Denmark. 25-26 November 2011
}

\section{Background}

Most of the available literature on cardiac arrests is dealing with treatment. In this cohort study, we have sought to describe the events surrounding cardiac arrests such as time, cause, initial rhythm, and the final outcome.

\section{Methods}

Retrospective analysis of all consecutive cardiac arrests at Sydvestjysk Sygehus Esbjerg in the years 2002 and 2007. The events were initially identified using a registry in the Department of Anaesthesia on all patient contacts. Using a unique personal identification number on all patients, we retrieved the charts and nurses notes and extracted the relevant data.

\section{Results}

We included 267 cardiac arrests, 175 out-of-hospital and 92 in-hospital arrests. The cardiac arrests were distributed with $21 \%$ in daytime (08-16), $27 \%$ in the evening (16-00) and $24 \%$ at night (00-08). The causes of cardiac arrests were acute coronary syndrome in $24 \%$, respiratory insufficiency in $13 \%$, hypotension in $5 \%$, arrhythmias in $3 \%$, other causes in $15 \%$ and unknown in 40 $\%$. The initial rhythm was asystole in $58 \%$, pulseless electrical activity in $18 \%$, pulseless ventricular tachycar$\mathrm{dia} /$ ventricular fibrillation in $15 \%$, rhythm with perfusion in $2 \%$ and unknown in $7 \%$. In three patients, the treatment was stopped because of a Do Not Attempt Resuscitation order in the chart. In 64 patients $(20 \%)$ the treatment was stopped due to return of spontaneous circulation and 30 (47 \%) patients survived to discharge.

\section{Conclusion}

Cardiac arrests at Sydvestjysk Sygehus Esbjerg occur around the clock with an even distribution during the day, evening and night. Most cardiac arrests are caused by acute coronary syndrome and respiratory failure. We most often witnessed asystole as the presenting rhythm. In-hospital arrests had a better chance of having return of spontaneous circulation. Even in patients with return of spontaneous circulation the final outcome is poor. There was no difference in the final outcome in 2002 and 2007.

\section{Author details}

'Department of Cardiology, Odense University Hospital, Denmark.

${ }^{2}$ Department of Anaesthesia, Odense University Hospital, Denmark.

${ }^{3}$ Department of Medicine, Sydvestjysk Sygehus Esbjerg, Denmark.

Published: 16 April 2012

doi:10.1186/1757-7241-20-S2-P2

Cite this article as: Ullerup-Aagaard et al:: A review of consecutive cardiac arrests in 2002 and 2007 at a regional hospital in Denmark: a retrospective cohort study. Scandinavian Journal of Trauma, Resuscitation and Emergency Medicine 2012 20(Suppl 2):P2. 